5. Козин И. В. Фрагментарные структуры и эволюционные алгоритмы. Питання прикладної математики і математичного моделювання. Дніпропетровськ, 2008. C. 138-146.

6. Dorigo M. Optimization, Learning, and Natural Algorithms. PhD Thesis, Dipartimento di Elettronica, Politechnico Di Milano, Italy. 1992. 140 p.

7. Moraglio A., Poli R. Inbreeding Properties of Geometric Crossover and Nongeometric Recombinations. Foundations of Genetic Algorithms. 2007. P. 1-14.

\title{
FRAGMENTAL MODEL PLACEMENT PRODUCTION
}

A two-dimensional problem of locating production objects in a discrete formulation is considered. It is shown that the discrete problem of locating production reduces to the problem of covering a graph with stars and has a fragmentary structure. To search for an approximate solution of the problem, a modification of the evolutionary algorithm on permutations with a geometric crossover operator and an ant colony algorithm on a fragmentary structure are proposed. The results of numerical experiment comparison of algorithms are given.

Key words: fragmented model, task of locating production, evolutionary algorithm, geometric crossover, ant colony algorithm.

Получено 29.01.2019

\section{УДК 519.8}

DOI: $10.32626 / 2308-5878.2019-19.41-46$

О. М. Коломис, канд. фіз.-мат. наук

Інститут кібернетики імені В. М. Глушкова НАН України, м. Київ

\section{ОЦІНКА ПОХИБКИ ЗАОКРУГЛЕННЯ АЛГОРИТМУ ОБЧИСЛЕННЯ ОЦІНКИ СПЕКТРАЛЬНОЇ ЩІЛЬНОСТІ}

У роботі розглянуто ефективні за швидкодією алгоритми обчислення оцінок спектральних щільностей стаціонарних ергодичних випадкових процесів із нульовим середнім значенням. Найчастіше для їх обчислення використовують метод прямого перетворення Фур'є з використанням алгоритму швидкого перетворення Фур'є (ШПФ). Стаття продовжує дослідження і обгрунтування цього методу в напрямку отримання більш якісних оцінок похибок заокруглення. Наведена оцінка похибки заокруглення алгоритму обчислення оцінки спектральної щільності.

Ключові слова: оцінка спектральної щуільності, похибка заокруглення, швидке перетворення Фур'є.

Вступ. Швидкі алгоритми розв'язання задач спектрального і кореляційного аналізу випадкових процесів почали з'являтися, в основному, після 1965 року, коли в обчислювальну практику увійшов алгоритм ШПФ $[1,2] .3$ його появою розроблено ряд обчислювальних 
алгоритмів прискореного розв'язання деяких задач цифрової обробки сигналів, побудовані ефективні за швидкодією алгоритми обчислення таких оцінок імовірнісних характеристик об'єктів керування, як оцінок згорток, кореляційних функцій, спектральних щільностей стаціонарних і деяких типів нестаціонарних випадкових процесів $[2,3]$.

Постановка задачі та алгоритм розв'язання. Нехай $x(t)-$ випадковий стаціонарний ергодичний процес 3 нульовим середнім значенням і задана вибірка $x_{v}=x\left(t_{v}\right), v=\overline{0, N-1}$. Для отримання оцінки спектральної щільності використовуємо співвідношення [2]

$$
S_{x}(k)=S_{x}\left(\omega_{k}\right)=\frac{h}{N}\left|\hat{X}_{k}\right|^{2}, k=\overline{0, N-1},
$$

де $h$ - крок часу, $\hat{X}_{k}=\hat{X}\left(\omega_{k}\right)$ - дискретне перетворення Фур'є (ДПФ) початкового сигналу $x(t), \omega_{k}=k /(N h), k=\overline{0, N-1}$. Для обчислення $\hat{X}_{k}, k=\overline{0, N-1}$ будемо використовувати алгоритм ШПФ

$$
\hat{X}_{k}=\hat{X}\left(\omega_{k}\right)=\sum_{v=0}^{N-1} x_{v} W_{N}^{v k},
$$

де $k, v=\overline{0, N-1}, W_{N}=e^{-i \frac{2 \pi}{N}}$.

Відомо [2], що евклідова норма оцінки похибки заокруглення алгоритму ШПФ обчислення ДПФ $\hat{X}=\left\{\hat{X}_{k}\right\}_{0}^{N-1}$ сигналу $x=\left\{x_{v}\right\}_{0}^{N-1}$, для $N=2^{\gamma}, \gamma>0$ — ціле, і класичному правилу заокруглення має вигляд

$$
\left\|E_{\hat{X}}\right\|_{E}<8 \cdot 1,06 \cdot \gamma \cdot 2^{-\tau} \cdot\|\hat{X}\|_{E} .
$$

Величину $S_{x}(k), k=\overline{0, N-1}$, що визначається у вигляді співвідношення (1), називають первинною оцінкою спектральної щільності. Ця оцінка $є$ досить «грубою», оскільки відбувається велике «просочування енергії» через бокові пелюстки за рахунок розширення головного пелюстка. Зазвичай прагнуть локалізувати енергію на центральній частоті, зменшуючи іiї «витік» у бокові пелюстки. Цього можна досягти, помноживши часову послідовності $x_{v}$ на деяке вікно даних (вагові послідовності) $d_{v}=d(v), v=\overline{0, N-1}$. Тоді отримаємо [2]:

$$
x_{d, v}=x_{d}(v)=x(v) \cdot d(v)=x_{v} \cdot d_{v}, v=\overline{0, N-1} .
$$

Спектральна щільність визначається виразом

$$
S_{x}^{*}(k)=S_{x}^{*}\left(\omega_{k}\right)=S_{x_{d}}(k)=\frac{h}{N}\left|\hat{X}_{d, k}\right|^{2},
$$


де

$$
\hat{X}_{d, k}=\hat{X}_{d}(k)=\sum_{v=0}^{N-1} x_{d, v} W_{N}^{v k}=\sum_{v=0}^{N-1} x_{v} \cdot d_{v} \cdot W_{N}^{v k},
$$

$\hat{X}_{d, k}$ - ДПФ сигналу $x_{d, v}, v=\overline{0, N-1}$.

Вікна даних зменшують відхилення амплітуди і дисперсію сигналу. Це призводить до погіршення оцінки спектра. Для отримання асимптотично незміщеної первинної оцінки спектральної щільності застосовується ваговий множник $Q$, який дає спектральне вікно одиничної площі. Отже, якщо застосовується згладжування даних, то оцінка спектральної щільності визначається виразом

$$
\hat{S}_{x}^{*}(k)=\hat{S}_{x}^{*}\left(\omega_{k}\right)=S_{x}^{*}(k) / Q,
$$

де $Q=\frac{1}{N} \sum_{v=0}^{N-1} d^{2}(v)$.

Таким чином, зміна спектра, викликана вживанням вікон даних компенсується введенням множника $1 / Q$.

Для отримання остаточних згладжених оцінок спектральної щільності $\hat{S}_{x}(k)=\hat{S}_{x}\left(\omega_{k}\right), k=\overline{0, N-1}$, які мають кращі статистичні властивості і придатні для практичного використання, слід провести подальше згладжування в частотній області, використовуючи згладжуючі функції $[2,3]$

$$
\hat{S}_{x}(k)=\hat{S}_{x}\left(\omega_{k}\right)=P\left(\hat{S}_{x}^{*}(k), j\right)
$$

де $P\left(\hat{S}_{x}^{*}(k), j\right)$ — функція, що здійснює згладжування первинної спектральної щільності $\hat{S}_{x}^{*}(k)$ в частотній області, $j$ - деякий параметр.

У роботах [2, 3] наведені сімейства вікон даних і вікон частот, які найчастіше застосовуються на практиці. Наприклад, наведені чотири сімейства вікон даних: алгебраїчне, узагальнене косинусоїдальне, гауссове і подібне до кореляційних вікон Хеммінга. Як згладжуючі функції $P=P\left(\hat{S}_{x}^{*}(k), j\right)$ в частотній області застосовують наступні: просте згладжування, згладжування $з$ трикутною вагою, згладжування $з$ косинусоїдальним вікном, усереднення за відрізками реалізації та комбінований спосіб усереднення за частотами та за відрізками.

Розглянемо алгоритм, який дозволяє (за ознакою) обчислювати або $S_{x}(k)$, або $S_{x}^{*}(k)$, або $\hat{S}_{x}^{*}(k)$, або $\hat{S}_{x}(k), k=\overline{0, N-1}$, причому в ньому можуть бути використані вікна як для даних, так і для частот $[2,4]$. Основні кроки алгоритму. 
Крок 1. «Набивка» $L$ нулями вихідної послідовності $x_{v}$, $v=\overline{0, N_{1}-1}$, так щоб $N_{1}=N+L=2^{\gamma}, \gamma>0$ - ціле, у випадку, якщо $N \neq 2^{\gamma}$.

Крок 2. Обчислення (за ознакою) ДПФ $\hat{X}_{k}, k=\overline{0, N_{1}-1}$ отриманої послідовності $x_{v}, v=\overline{0, N_{1}-1}$, згідно співвідношення (2) з використанням алгоритму ШПФ.

Крок 3. Обчислення $S_{x}(k), k=\overline{0, N_{1}-1}$ згідно співвідношення (1). Перехід на крок 8.

Крок 4. Згладжування (за ознакою) отриманої на кроці 1 послідовності $x_{v}$, за допомогою вікон даних $d_{v}, v=\overline{0, N_{1}-1}$ (див. співвідношення (3)) та отримання послідовності $x_{d, v}=x_{v} \cdot d_{v}, v=\overline{0, N_{1}-1}$.

Крок 5. Обчислення ДПФ $\hat{X}_{d, k}$ послідовності $x_{d, v}$, $v, k=\overline{0, N_{1}-1} \quad 3$ використанням алгоритму ШПФ та отримання $S_{x}^{*}(k), k=\overline{0, N_{1}-1}$ згідно співвідношення (4).

Крок 6. Обчислення оцінки спектральної щільності $\hat{S}_{X}^{*}\left(\omega_{k}\right)$ згідно співвідношення (6), $k=\overline{0, N_{1}-1}$. Перехід за ознакою на крок 7 або 8.

Крок 7. Згладжування $\hat{S}_{x}^{*}(k), k=\overline{0, N_{1}-1}$ (за ознакою) за допомогою вікон частот та отримання згладженої оцінки спектральної щільності $\hat{S}_{x}(k)$ згідно співвідношення (7), $k=\overline{0, N_{1}-1}$.

Крок 8. Кінець.

Основними характеристики наведеного алгоритму обчислення оцінок спектральної щільності є точність та обчислювальна складність. В роботі основна увага приділена аналізу точності, тобто, отриманню оцінок похибок, що супроводжують процес обчислення оцінки спектральної щільності. Для оцінки точності запропонованого алгоритму обчислення спектральних щільностей дослідимо лише оцінку похибки заокруглення $E_{3}$, що виникає при реалізації обчислювального алгоритму на комп'ютері для класичного правила заокруглення, для обчислень у режимі плаваючої коми $з \tau$ розрядами в мантисі числа.

Оцінка похибки заокруглення алгоритму обчислення $S_{x}(k)$, $k=\overline{0, N-1}$. Нехай $N=2^{\gamma}, \quad \gamma>0$ - ціле, $x_{v}=x\left(t_{v}\right), \quad v=\overline{0, N-1}$ вибірка стаціонарного ергодичного випадкового процесу $x(t) 3$ нульовим середнім значенням, $f l(*)$ - результат обчислення виразу, 
який стоїть у дужках на ЕОМ у режимі 3 плаваючою комою $3 \tau$ розрядами у мантисі числа, $\|*\|_{E}-$ евклідова норма вектора. Справедлива така теорема [5].

Теорема 1. Оцінка евклідової норми похибки заокруглення обчислення $S_{x}(k), k=\overline{0, N-1}$, згідно виразу (1) за допомогою алгоритму ШПФ для режиму з плаваючою комою $3 \tau$ розрядами у мантисі числа має вигляд

$$
\left\|E_{3, S_{x}}\right\|_{E} \sim 8 \cdot 1,06 \cdot \gamma \cdot 2^{-\tau} \cdot h \cdot\|x\|_{E}^{2}\left[1+1,06 \cdot 2^{-\tau}(16 \gamma+\sqrt{N})\right] .
$$

Оцінка похибки заокруглення алгоритму обчислення $\hat{S}_{x}^{*}(k)$, $k=\overline{0, N-1}$. Нехай $\varepsilon_{d, v}=\varepsilon_{d}(v), e_{x_{d, v}}=e_{x_{d}}(v)-$ похибки заокруглення, які виникають при обчисленні відповідно $d_{v}$ та $x_{d, v}$ за допомогою співвідношення (4) в режимі $з$ плаваючою комою $3 \tau$ розрядами у мантисі числа, $\hat{X}_{d, k}$ та $\hat{d}_{k}-$ ДПФ відповідно послідовностей $x_{d, v}$ та $d_{v}, v=\overline{0, N-1}$, які обчислюються за допомогою ШПФ з похибками заокруглення відповідно $E_{\hat{X}_{d, k}}=E_{\hat{X}_{d}}(k)$ та $E_{\hat{d}, k}=E_{\hat{d}}(k), E_{Q}-$ похибка заокруглення обчислення масштабуючого множника $Q$. Справедлива наступна теорема [6].

Теорема 2. Оцінка евклідової норми похибки заокруглення обчислення оцінки спектральної щільності $\hat{S}_{x}^{*}(k), k=\overline{0, N-1}$, згідно співвідношень (4)-(7) за допомогою алгоритму ШПФ, для режиму 3 плаваючою комою $3 \tau$ розрядами у мантисі числа має вигляд

$$
\begin{aligned}
\left\|E_{3, \hat{S}_{x}^{*}}\right\|_{E} \sim & \frac{h}{Q} 8 \cdot 1,06 \cdot \gamma \cdot 2^{-\tau}\|x\|_{E}^{2}\|d\|_{E}\left\{\| d \| _ { E } \left(1+\left\|E_{Q}\right\|_{E}+1,06 \cdot 2^{-\tau+2} \times\right.\right. \\
& \left.\times[\sqrt{N}+4 \gamma])+2 \sqrt{N}\left\|\varepsilon_{d}\right\|_{E}\left(8 \cdot 1,06 \cdot 2^{-\tau} \gamma+1\right)\right\} .
\end{aligned}
$$

Із більш детального аналізу алгоритму ШПФ випливає, що виграш у кількості арифметичних операцій у порівнянні зі стандартним способом виходить ще більшим, оскільки багато множників вигляду $W_{N}^{k r}$ мають в «метеликах» значення $\pm 1, \pm i$, завдяки чому виключаються відповідні операції множення.

Доведено, що при $N=2^{\gamma}$ оцінка знизу (серед всіх алгоритмів обчислення ДПФ) кількості операцій додавання рівна $\frac{N}{2} \log _{2} N$. Iснують також алгоритми і програми обчислення багатовимірного ДПФ за допомогою ШПФ. 


\section{Список використаних джерел:}

1. Cooley J. W., Tukey J. W. An algorithm for the machine calculation of complex Fourier Series. Math. Comput., 1965, Apr. P. 257-301.

2. Задирака В. К. Теория вычисления преобразования Фурье. Киев : Наук. думка, 1983. $216 \mathrm{c.}$

3. Сергієнко І. В., Задірака В. К., Литвин О. М., Мельникова С. С., Нечуйвітер О. П. Оптимальні алгоритми обчислення інтегралів від швидкоосцилюючих функцій та їх застосування. Т. 2. Застосування. Київ : Наук. думка, 2011.348 с.

4. Коломис О. М., Луц Л. В. Алгоритм обчислення оцінок спектральної щільності. Питання оптимізаиії обчислень (ПОО-XLII): праџฺі міжнар. наук. школи-семінару, присвяченої 85-річчю від дня народження академіка В.С. Михалевича (21-25 вересня 2015 р.). Київ : Інститут кібернетики імені В.М. Глушкова НАН України, 2015. С. 45-46.

5. Коломис О. М. Оцінка похибки заокруглення алгоритму обчислення первинної оцінки спектральної щільності. Математичне та комп'ютерне моделювання. Серія: Фізико-математичні науки. 2017. Вип. 15. С. 80-84.

6. Коломис О. М. Ефективні за точністю та швидкодією алгоритми визначення оцінок динамічних та імовірнісних характеристик неперервних виробничих процесів. Дисертація на здобуття наукового ступеня канд. фіз.мат. наук. Київ, 2015. 172 с.

\section{ESTIMATION OF THE ROUNDING ERROR OF THE ALGORITHM FOR CALCULATING THE ESTIMATE OF THE SPECTRAL DENSITY}

The estimation of the rounding error of the algorithm for calculating the estimate of the spectral density are developed.

Key words: the estimate of the spectral density, rounding error, fast Fourier Transform. 